\title{
Complete Shaking Force and Shaking Moment Balancing of In-line Four-bar Linkages by adding a Class-two RRR or RRP Assur Group
}

\author{
Sébastien Briot ${ }^{1}$ (corresponding author) \& Vigen Arakelian ${ }^{2}$ \\ ${ }^{1}$ Institut de Recherches en Communications et Cybernétique de Nantes (IRCCyN) \\ IRCCyN, Bureau 416, \\ 1 rue de la Noё, \\ BP 92101, F-44321 Nantes Cedex 03 \\ FRANCE \\ Sebastien.Briot@irccyn.ec-nantes.fr \\ Phone : $33(0) 240376958$ \\ Fax: $+33(0) 240376930$ \\ ${ }^{2}$ M\&CSM Department \\ Institut National des Sciences Appliquées (I.N.S.A.) \\ vigen.arakelyan@insa-rennes.fr
}

\begin{abstract}
This paper deals with the complete shaking force and shaking moment balancing of planar in-line four-bar linkages with constant input speed. A new solution is discussed, which is carried out without counter-rotations. The complete shaking force and shaking moment balancing is obtained by using a coupler link, which is a physical pendulum and by adding a class-two Assur group with prescribed geometrical and mass parameters. Two types of Assur group are examined: two links group with three revolute joints (RRR) and two links group with two revolute and one prismatic joints (RRP). Numerical simulations carried out using ADAMS software validate the proposed balancing technique and illustrate that the obtained six-bar mechanism is reactionless, i.e. the sum of all ground bearing forces and their moments are eliminated.
\end{abstract}

Keywords: Shaking force, shaking moment, balancing, planar linkage, Assur group.

\section{Introduction}

When an unbalanced linkage must run at high speeds, or contains massive links, considerable shaking force and shaking moment are transmitted to its surroundings. These disturbances cause vibrations and therefore limit the full potential of many machines. Many high-speed machines contain planar four-bar linkages and the problem of their mass balancing is of continuing interest to machine designers. The previous works on the balancing of planar fourbar linkages may be arranged in the following groups.

(i) Complete shaking force balancing [1]-[7]. In general, it is carried out by counterweights mounted on the movable links of the linkage. With regards to the several approaches employed for the redistribution of movables masses, the developed methods could be divided into three principal groups. a) The method of «principal vectors» [1]; The aim of this approach was to study the balancing of the mechanism relative to each link and in the determination of those points on the links relative to which a static balance was obtained. These points were called «principal points». Then, from the condition of similarity of the vector loop of the principal points and the structural loop of the mechanism, the necessary conditions of balancing were derived. $b$ ) The method of «static substitution of masses»; its aim was to statically substitute the mass of the coupler by concentrated masses, which are balanced thereafter together with the rotating links. Such an approach changes the problem of mechanism balancing into a simpler problem of balancing rotating links. This method was illustrated for four-bar linkage in [2]-[5]. 
c) The method of «linearly independent vectors» [6], in which the vector equation describing the position of the center of total mass of the mechanism is treated in conjunction with the closed equation of its kinematic chain. The result is an equation of static moments of moving link masses containing single linearly independent vectors. Thereafter following the conditions for balancing the mechanism by reducing the coefficients, which are time-dependent to zero.

It should be noted that the addition of a counterweighted pantograph device to the planar four-bar linkage has also been used for its complete shaking force balancing [7].

(ii) Complete shaking force and partial shaking moment balancing [8]-[17]. Two principal approaches may be distinguished: $a$ ) the shaking moment minimization of fully force balanced linkages [8]-[14], in which it is shown that the optimum conditions of partial moment balance can be obtained by certain link mass distribution ratios. $b$ ) the minimization of the unbalance of shaking moment by transferring the rotation axis of the counterweight mounted on the input crank [15]-[17]. In the study [15], the first harmonic of the shaking moment is eliminated by attaching the required input link counterweight, not to the input shaft itself, but to a suitable offset one which rotates with the same angular velocity. This approach is original in that, while maintaining the force balance of the mechanism, it is possible to create an additional balancing moment, thereby reducing the shaking moment. This approach has been further developed in works [16], [17].

It should be noted that optimization algorithms are also widely used in partial balancing of four-bar linkages [18]-[21].

(iii) Complete shaking force and shaking moment balancing [22]-[32]. The first method of complete shaking force and shaking moment balancing was proposed in study [22], which was extended in [23]. In this approach, the mass of the connecting coupler is substituted dynamically by concentrated masses located at the coupler joints. Thus, the dynamic model of the coupler becomes a weightless link with two concentrated masses. This transforms the problem of fourbar linkage shaking force and shaking moment balancing into a problem of balancing rotating links carrying concentrated masses. The parallelogram structure has also been applied for complete shaking force and shaking moment balancing of four-bar linkages [24]. In the studies [25]-[29], the authors have proposed methods for complete shaking force and shaking moment balancing by counterweights with planetary gear trains. In [30] a toothed-belt transmission is used to rotate counterweights intended for shaking force balancing, which also allows shaking moment balancing. The disadvantage of these methods is the need for the connection of gears to the oscillating links. The oscillations of the links of the mechanism will create noise unless expensive anti-backlash gears are used.

Another solution using the copying properties of the pantograph was developed [31], [32], in which the gears driven by the coupler suffer no such sudden reversals so that this problem is almost eliminated. However, it should be noted that the use of the gears for the balancing of four-bar linkages is a drawback for the industrial applications and a fully shaking force and shaking moment balanced four-bar linkage without any gears is more appealing.

The shaking moment balancing of fully force balanced linkages using a prescribed input speed fluctuation was proposed in [33]. However, such balancing is complicated because it is necessary to use a special type of drive generator. Moreover, it cannot be used for balancing of linkages, which generate the prescribed motions of the output links.

In this paper a new solution is discussed, which allows the complete shaking force and shaking moment balancing of in-line ${ }^{1}$ four-bar linkages with constant input speed by adding a class-two Assur group, i.e. a group which does not add any supplementary degree of freedom into the mechanism [34]. It should be noted that the balancing of the shaking moment without counter-rotations of three particular classes of four-bar linkages was discussed in the studies

\footnotetext{
${ }^{1}$ The term 'in-line' means that the centres of mass of the links must lie on the line connecting the pivots (which can be extended beyond the pivots). The links need not be symmetrical in any way [23].
} 
[35]-[38]. However, such a method cannot be extended to general four-bar linkages. In this paper it is proposed to take advantages of the use of the properties of the four-bar linkage with prescribed geometric parameters [35]-[38] and to combine it with (i) the principle of the dynamic substitution of link mass by concentrated masses and (ii) with the prescription of constant input speed. It should be mentioned here that the suggested balancing approach can be efficiently applied on the cyclic high-speed machines executing motions in the steady-state regime when the input speed is constant [39], [40].

\section{Complete shaking force and shaking moment balancing by adding a class-two RRR Assur group}

2.1. Theoretical background related to the balanced four-bar linkages with prescribed geometrical parameters.

Before considering the suggested balancing concept, let us recall basic notions concerning the balanced four-bar linkages with prescribed geometrical parameters.

In the paper of Berkof and Lowen [8], the angular momentum $H$ and the shaking moment $M$, expressed at point $O$, of a force balanced in-line four-bar linkage (Fig. 1) were expressed as:

$$
H=\sum_{i=1}^{3} I_{i} \dot{\theta}_{i}, M=\frac{d}{d t}(H)=\sum_{i=1}^{3} I_{i} \ddot{\theta}_{i}
$$

with

$$
\begin{gathered}
I_{i}=m_{i}\left(k_{i}^{2}+r_{i}^{2}+r_{i} l_{i}\right),(i=1 \text { and } 3) \\
I_{2}=m_{2}\left(k_{2}^{2}+r_{2}^{2}-r_{2} l_{2}\right),
\end{gathered}
$$

where $r_{i}$ is the length of vector $\mathbf{r}_{i}$ which connects the pivot $P_{i}$ to the centre of mass of link $i, l_{i}$ is the length of vector $\mathbf{l}_{i}$ which connects the proximal revolute joint $P_{i}$ to the distal joint on the same link, $d$ is the length of the base which is the distance between the two fixed joints on the base, and $k_{i}$ is the radius of gyration with respect to the centre of mass of link $i, m_{i}$ is the mass of link $i$. Moreover, $\theta_{i}$ is the angular position of link $i$ with respect to the $\boldsymbol{x}$-axis.

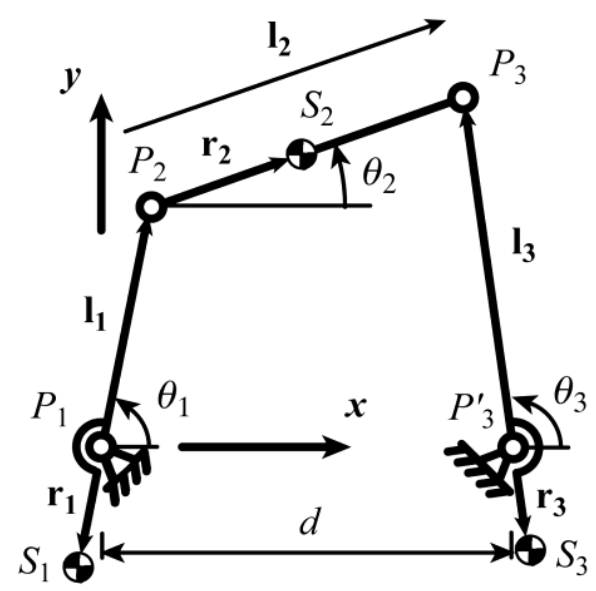

Fig. 1. A general in-line four-bar mechanism.

It should be carefully noted that the terms $I_{i}$ of equations (2) and (3) should not be mistaken for the moment of inertia of a link, even if the units are the same.

With regard to the shaking force balancing, the following expressions were obtained:

$$
m_{1} r_{1}=m_{2}\left(l_{2}-r_{2}\right) l_{1} / l_{2},
$$




$$
m_{3} r_{3}=m_{2} r_{2} l_{3} / l_{2}
$$

In the works [35], [36], it has been shown that it is possible to cancel the shaking moment of a four bar mechanism by associating mentioned geometric constraints with an optimal distribution of masses. Three kinds of shaking force and shaking moment balanced four-bar mechanisms were found, which are shown in Fig. 2.

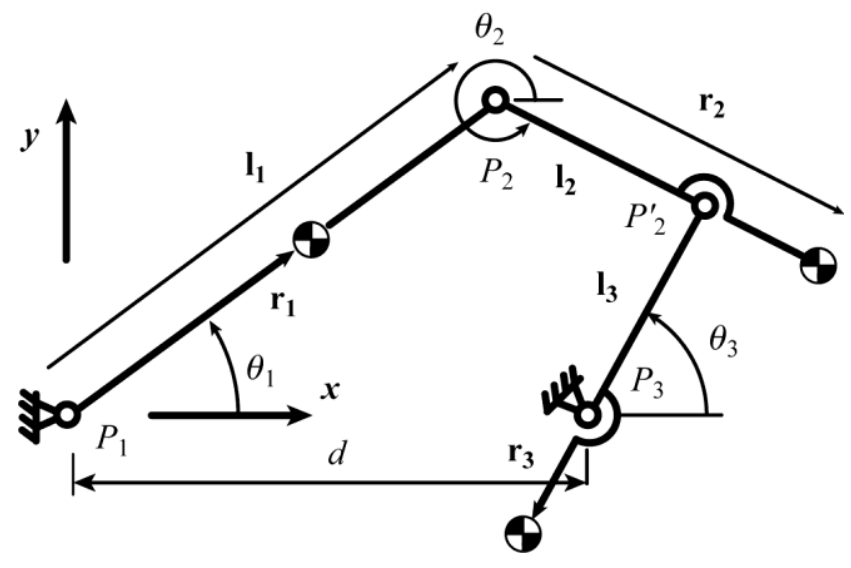

(a) Case I: $l_{1}=d$ and $l_{2}=l_{3}$

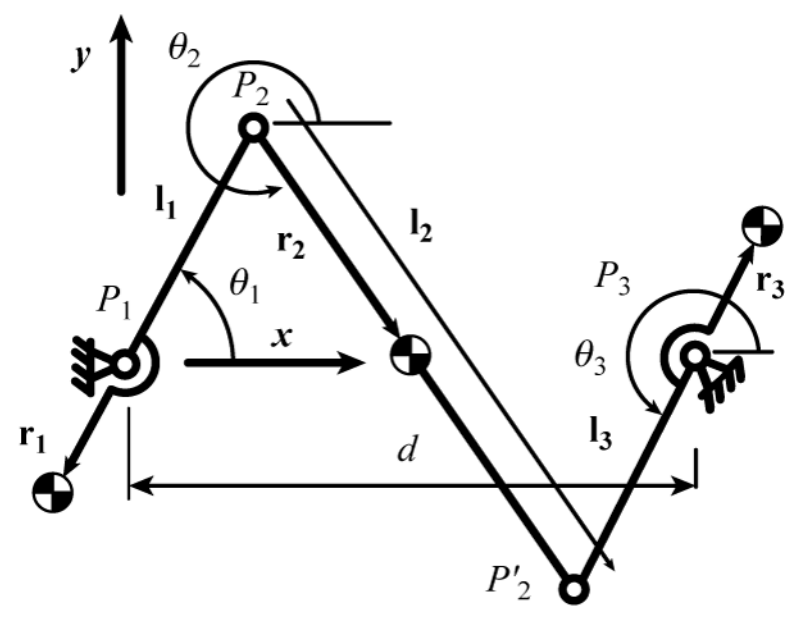

(b) Case II: $l_{1}=l_{3}$ and $l_{2}=d$

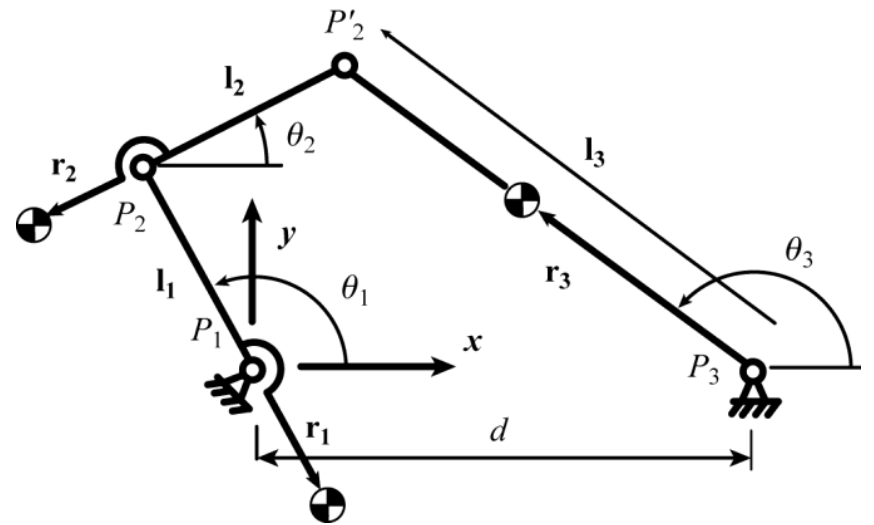

(c) Case III: $l_{1}=l_{2}$ and $l_{3}=d$

Fig. 2. The three kinds of shaking force and shaking moment balanced four-bar mechanisms.

In order to illustrate the shaking moment balancing, let us consider the mechanism shown in Fig. 2b. The geometrical constraints of this mechanism are the following:

$$
\begin{aligned}
& l_{1}=l_{3}, \\
& d=l_{2} .
\end{aligned}
$$

This leads to the following kinematic relationships:

$$
\dot{\theta}_{1}-\dot{\theta}_{2}+\dot{\theta}_{3}=0 \text {. }
$$

Thus, from expressions (1) and (8), it is easy to see that the shaking moment will be cancelled if $I_{1}=-I_{2}=I_{3}$ (see Eqs. (2) and (3)). For this purpose the following relationships must be established [34]:

$$
\begin{array}{r}
k_{2}^{2}=\frac{m_{2}\left(l_{2} r_{2}-r_{2}^{2}\right)-I_{1}}{m_{2}}, \\
k_{3}^{2}=\frac{-m_{3}\left(l_{3} r_{3}+r_{3}^{2}\right)+I_{1}}{m_{3}},
\end{array}
$$

where 


$$
I_{1}=m_{1}\left(k_{1}^{2}+r_{1}^{2}+r_{1} l_{1}\right)
$$

It should be noted that similar results have been obtained for the mechanisms shown in Figs. $2 \mathrm{a}$ and $2 \mathrm{c}$.

\section{Statement of the problem}

The aim of the suggested balancing approach consists of adding a two-link kinematic chain with prescribed geometrical parameters to an in-line four-bar linkage with arbitrary geometrical parameters. It is important to note that the added structure must be an Assur group, i.e. a group which does not add any supplementary degree of freedom into the mechanism [34]. This allows for the modification of the mass redistribution of the obtained six-bar mechanism without perturbation of the kinematic properties of the initial four-bar linkage. We would like to restate that this technique allows for the complete shaking force and shaking moment balancing without counter-rotating masses.

Now let us consider the shaking force and shaking moment balancing of an in-line four-bar mechanism using class-two Assur groups with RRR kinematic chain.

\subsection{Shaking force balancing}

Fig. 3 shows an in-line four-bar linkage with the added class-two RRR Assur group. Let us denote the following vectors as: $\mathbf{l}_{\mathbf{1}}=\mathbf{d}_{O A}, \mathbf{l}_{\mathbf{2}}=\mathbf{d}_{A B}, \mathbf{l}_{\mathbf{3}}=\mathbf{d}_{C B}, \mathbf{l}_{\mathbf{3}}=\mathbf{d}_{C P 2}, \mathbf{l}_{\mathbf{4}}=\mathbf{d}_{P 2 P^{\prime} 2}, \mathbf{l}_{\mathbf{5}}=\mathbf{d}_{P 3 P^{\prime} 2}, \mathbf{r}_{\mathbf{1}}=$ $\mathbf{d}_{O S 1}, \mathbf{r}_{\mathbf{2}}=\mathbf{d}_{A S 2}, \mathbf{r}_{\mathbf{3}}=\mathbf{d}_{C S 3}, \mathbf{r}_{\mathbf{4}}=\mathbf{d}_{P 2 S 4}, \mathbf{r}_{\mathbf{5}}=\mathbf{d}_{P 3 S 5}, \mathbf{r}_{\mathbf{C P 1}}=\mathbf{d}_{O S C P 1}, \mathbf{r}_{\mathbf{C P 2}}=\mathbf{d}_{C S C P 2}, \mathbf{r}_{\mathbf{C P 3}}=\mathbf{d}_{P 3 S C P 3}$. The notation $\mathbf{d}_{P Q}$ represents the vector starting from from $P$ to point $Q$.

The added class-two RRR Assur group has the above mentioned properties, i.e. it is designed such as:

$$
\begin{gathered}
l_{3}^{\prime}=l_{5}, \\
e=l_{4},
\end{gathered}
$$

where $l_{i}\left(i=3\right.$ to 5 ) is the norm of vector $\mathbf{l}_{i}$ and $e$ the distance between $C$ and $P_{3}$.

As it is shown in Fig. 3, the Assur group $P_{2} P_{2}{ }_{2} P_{3}$ is attached to the initial linkage $O A B C$ in such a way that it forms a four-bar linkage with link $(B C)$, discussed in paragraph 2.1.

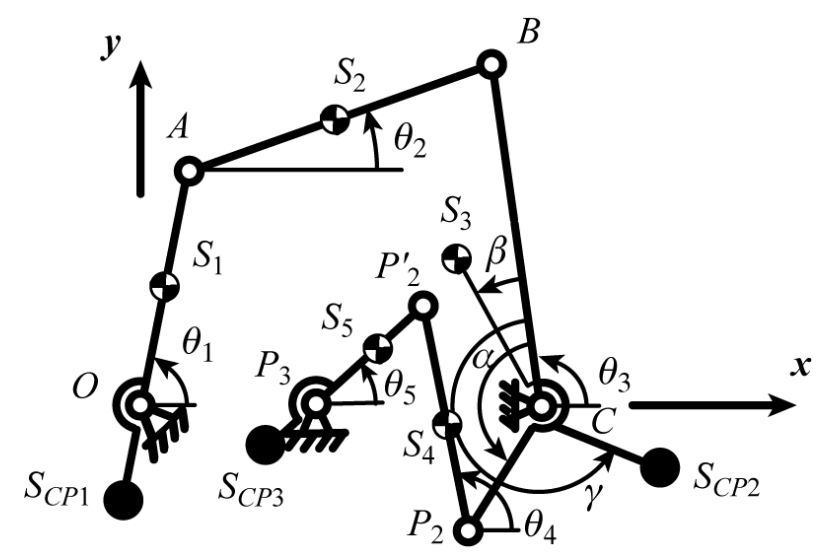

Fig. 3. The balanced mechanism with the class-two RRR Assur group.

Let us now derive the expression of the shaking force $\mathbf{F}_{s h}$ of the obtained mechanism:

$$
\mathbf{F}_{s h}=\sum_{i=1}^{5} m_{i} \ddot{\mathbf{d}}_{S i}
$$


where $m_{i}$ is the mass of the link $i$ and $\ddot{\mathbf{d}}_{S i}$ the translational acceleration of the centre of mass $S_{i}$. Developing and simplifying, one obtains:

$$
\mathbf{F}_{s h}=\left(m_{1} \frac{r_{1}}{l_{1}}+m_{2} \frac{l_{2}-r_{2}}{l_{2}}\right) \ddot{\mathbf{d}}_{A}+m_{2} \frac{r_{2}}{l_{2}} \ddot{\mathbf{d}}_{B}+m_{3} \ddot{\mathbf{d}}_{s 3}+m_{4} \frac{l_{4}-r_{4}}{l_{4}} \ddot{\mathbf{d}}_{P 2}+\left(m_{4} \frac{r_{4}}{l_{4}}+m_{5} \frac{r_{5}}{l_{5}}\right) \ddot{\mathbf{d}}_{P^{\prime} 2}
$$

where $r_{i}$ is the algebraic values of the norm of vectors $\mathbf{r}_{i}$, and $\ddot{\mathbf{d}}_{A}, \ddot{\mathbf{d}}_{B}, \ddot{\mathbf{d}}_{S 3}, \ddot{\mathbf{d}}_{P 2}$ and $\ddot{\mathbf{d}}_{P^{\prime} 2}$ represent the acceleration of points $A, B, S_{3}, P_{2}$ and $P^{\prime}{ }_{2}$ respectively. Their expressions are:

$$
\begin{gathered}
\ddot{\mathbf{d}}_{A}=l_{1}\left(\ddot{\theta}_{1}\left[\begin{array}{c}
-\sin \theta_{1} \\
\cos \theta_{1}
\end{array}\right]-\dot{\theta}_{1}^{2}\left[\begin{array}{c}
\cos \theta_{1} \\
\sin \theta_{1}
\end{array}\right]\right), \\
\ddot{\mathbf{d}}_{B}=l_{3}\left(\ddot{\theta}_{3}\left[\begin{array}{c}
-\sin \theta_{3} \\
\cos \theta_{3}
\end{array}\right]-\dot{\theta}_{3}^{2}\left[\begin{array}{c}
\cos \theta_{3} \\
\sin \theta_{3}
\end{array}\right]\right), \\
\ddot{\mathbf{d}}_{S 3}=r_{3}\left(\ddot{\theta}_{3}\left[\begin{array}{c}
-\sin \left(\theta_{3}+\beta\right) \\
\cos \left(\theta_{3}+\beta\right)
\end{array}\right]-\dot{\theta}_{3}^{2}\left[\begin{array}{c}
\cos \left(\theta_{3}+\beta\right) \\
\sin \left(\theta_{3}+\beta\right)
\end{array}\right]\right), \\
\ddot{\mathbf{d}}_{P 2}=l_{3}^{\prime}\left(\ddot{\theta}_{3}\left[\begin{array}{c}
-\sin \left(\theta_{3}+\alpha\right) \\
\cos \left(\theta_{3}+\alpha\right)
\end{array}\right]-\dot{\theta}_{3}^{2}\left[\begin{array}{c}
\cos \left(\theta_{3}+\alpha\right) \\
\sin \left(\theta_{3}+\alpha\right)
\end{array}\right]\right), \\
\ddot{\mathbf{d}}_{P^{\prime} 2}=l_{5}\left(\ddot{\theta}_{5}\left[\begin{array}{c}
-\sin \theta_{5} \\
\cos \theta_{5}
\end{array}\right]-\dot{\theta}_{5}^{2}\left[\begin{array}{l}
\cos \theta_{5} \\
\sin \theta_{5}
\end{array}\right]\right) .
\end{gathered}
$$

The shaking force $\mathbf{F}_{s h}$ may be cancelled through the addition of three counterweights positioned at points $S_{C P i}$ (Fig. 3), with masses $m_{C P i}(i=1,2,3)$. With such counterweights, the expression of the shaking force becomes:

$$
\mathbf{F}=\mathbf{F}_{s h}+\mathbf{F}_{C W}=\mathbf{F}_{s h}+m_{C P 1} \frac{r_{C P 1}}{l_{1}} \ddot{\mathbf{d}}_{A}+m_{C P 2} \ddot{\mathbf{d}}_{C P 2}+m_{C P 3} \frac{r_{C P 3}}{l_{5}} \ddot{\mathbf{d}}_{P^{\prime} 2},
$$

where $r_{C P i}$ is the algebraic values of the norm of vectors $\mathbf{r}_{\mathbf{C P} i}$ and

$$
\ddot{\mathbf{d}}_{C P 2}=r_{C P 2}\left(\ddot{\theta}_{3}\left[\begin{array}{c}
-\sin \left(\theta_{3}+\gamma\right) \\
\cos \left(\theta_{3}+\gamma\right)
\end{array}\right]-\dot{\theta}_{3}^{2}\left[\begin{array}{c}
\cos \left(\theta_{3}+\gamma\right) \\
\sin \left(\theta_{3}+\gamma\right)
\end{array}\right]\right) \text {. }
$$

Thus the shaking force is cancelled if the distribution of the masses is as follows:

$$
\begin{gathered}
m_{C P 1}=-\frac{l_{1}}{r_{C P 1}}\left(m_{1} \frac{r_{1}}{l_{1}}+m_{2} \frac{l_{2}-r_{2}}{l_{2}}\right), \\
\tan \gamma=\frac{m_{3} r_{3} \sin \beta+m_{4}\left(1-r_{4} / l_{4}\right) l_{3}^{\prime} \sin \alpha}{m_{2} l_{3} r_{2} / l_{2}+m_{3} r_{3} \cos \beta+m_{4}\left(1-r_{4} / l_{4}\right) l_{3}^{\prime} \cos \alpha}, \\
m_{C P 2}=\sqrt{\frac{\left(m_{3} r_{3} \sin \beta+m_{4}\left(1-r_{4} / l_{4}\right) l_{3}^{\prime} \sin \alpha\right)^{2}+\left(m_{2} l_{3} r_{2} / l_{2}+m_{3} r_{3} \cos \beta+m_{4}\left(1-r_{4} / l_{4}\right) l_{3}^{\prime} \cos \alpha\right)^{2}}{r_{C P 2}^{2}}} \\
m_{C P 3}=-\frac{l_{5}}{r_{C P 3}}\left(m_{4} \frac{r_{4}}{l_{4}}+m_{5} \frac{r_{5}}{l_{5}}\right) .
\end{gathered}
$$

\subsection{Shaking moment balancing}

Let us now derive the expression of the shaking moment $M$, expressed at point $O$, of such a mechanism: 


$$
M=\sum_{i=1}^{5} m_{i}\left(x_{S i} \ddot{y}_{S i}-y_{S i} \ddot{x}_{S i}+k_{i}^{2} \ddot{\theta}_{i}\right)+\sum_{i=1}^{3} m_{C P i}\left(x_{S C P i} \ddot{y}_{S C P i}-y_{S C P i} \ddot{x}_{S C P i}\right)
$$

where $x_{S i}, y_{S i}, \ddot{x}_{S i}$ and $\ddot{y}_{S i}$ are the position and accelerations along $\boldsymbol{x}$ and $\boldsymbol{y}$ axes of points $S_{i}$, respectively, and $x_{S C P i}, y_{S C P i}, \ddot{x}_{S C P i}$ and $\ddot{y}_{S C P i}$ are the position and accelerations along $\boldsymbol{x}$ and $\boldsymbol{y}$ axes of points $S_{C P i}$, respectively, $k_{i}$ is the radius of gyration of link $i$.

Now, let us consider that link 2 is a physical pendulum ${ }^{2}$ [23], i.e. it can be replaced dynamically by two point masses located at joint centres $A$ and $B$. This implies that:

$$
k_{2}^{2}=r_{2}\left(l_{2}-r_{2}\right) \text {. }
$$

Then, considering that the input speed is constant, i.e.

$$
\ddot{\theta}=0 \text {. }
$$

Taking into account Eqs. (20) and (21), one can simplify Eq. (19) as:

$$
M=\sum_{i=3}^{5} I_{i} \ddot{\theta}_{i}
$$

where

$$
\begin{gathered}
I_{3}=m_{3}\left(k_{3}^{2}+r_{3}^{2}\right)+m_{2} \frac{r_{2}}{l_{2}} l_{3}^{2}+m_{C P 2} r_{C P 2}^{2}+m_{4} \frac{l_{4}-r_{4}}{l_{4}} l_{3}^{2}, \\
I_{4}=m_{4}\left(k_{4}^{2}+r_{4}^{2}-r_{4} l_{4}\right), \\
I_{5}=m_{5}\left(k_{5}^{2}+r_{5}^{2}-r_{C P 3} r_{5}\right)+m_{4} r_{4} l_{5}\left(l_{5}-r_{C P 3}\right) / l_{4} .
\end{gathered}
$$

Thus, this new six-bar mechanism has the same shaking moment as the four-bar mechanism composed of links $\left(P_{1} P_{2}\right),\left(P_{2} P_{2}^{\prime}\right)$ and $\left(P_{2}^{\prime} P_{3}\right)$. Therefore, the initial four-bar linkage balancing problem is transformed in the balancing of the four-bar linkage formed by the added Assur group. Note that the latter has specific geometry and its balancing conditions have been examined in section 2.1 .

Applying these results to the considered mechanism, we obtain:

$$
\begin{gathered}
k_{4}^{2}=\left(-I_{3}+r_{4} l_{4}-r_{4}^{2}\right) / m_{4}, \\
k_{5}^{2}=\frac{m_{5}\left(r_{C P 3} r_{5}-r_{5}^{2}\right)+m_{4} r_{4} l_{5}\left(r_{C P 3}-l_{5}\right) / l_{4}+I_{3}}{m_{5}} .
\end{gathered}
$$

Substitution of Eqs. (24)-(25) into eq. (22) leads to:

$$
M=I_{3}\left(\dot{\theta}_{3}-\dot{\theta}_{4}+\dot{\theta}_{5}\right)
$$

Taking into account relations (12) and (13), we have

$$
\ddot{\theta}_{3}-\ddot{\theta}_{4}+\ddot{\theta}_{5}=0 \text {. }
$$

and consequently

$$
M=0 \text {. }
$$

The proposed balancing technique has been illustrated using the four-bar linkage shown in Fig. 2b. However, it can also be achieved via the mechanism of Fig. 2a or Fig. 2c.

\footnotetext{
${ }^{2}$ A 'physical pendulum' is a link which has such a distribution of masses that it allows the dynamic substitution of link's mass and inertia by two concentrated masses.
} 


\section{Complete shaking force and shaking moment balancing by adding a class-two RRP Assur group}

\subsection{Shaking force balancing}

The second solution, which is proposed for the cancellation of the shaking moment of a four-bar linkage is carried out by adding a class-two RRP Assur group (Fig. 4). Let us denote the following vectors as: $\mathbf{l}_{\mathbf{1}}=\mathbf{d}_{O A}, \mathbf{l}_{\mathbf{2}}=\mathbf{d}_{A B}, \mathbf{l}_{\mathbf{3}}=\mathbf{d}_{C B}, \mathbf{l}_{\mathbf{3}}=\mathbf{d}_{C D}, \mathbf{l}_{\mathbf{4}}=\mathbf{d}_{D E}, \mathbf{r}_{\mathbf{1}}=\mathbf{d}_{O S 1}, \mathbf{r}_{\mathbf{2}}=\mathbf{d}_{A S 2}, \mathbf{r}_{\mathbf{3}}=$ $\mathbf{d}_{C S 3}, \mathbf{r}_{\mathbf{4}}=\mathbf{d}_{D S 4}, \mathbf{r}_{\mathbf{5}}=\mathbf{d}_{E S 5}, \mathbf{r}_{\mathrm{CP1}}=\mathbf{d}_{O S C P 1}, \mathbf{r}_{\mathbf{C P 2}}=\mathbf{d}_{C S C P 2}, \mathbf{r}_{\mathbf{C P 3}}=\mathbf{d}_{D S C P 3}$.

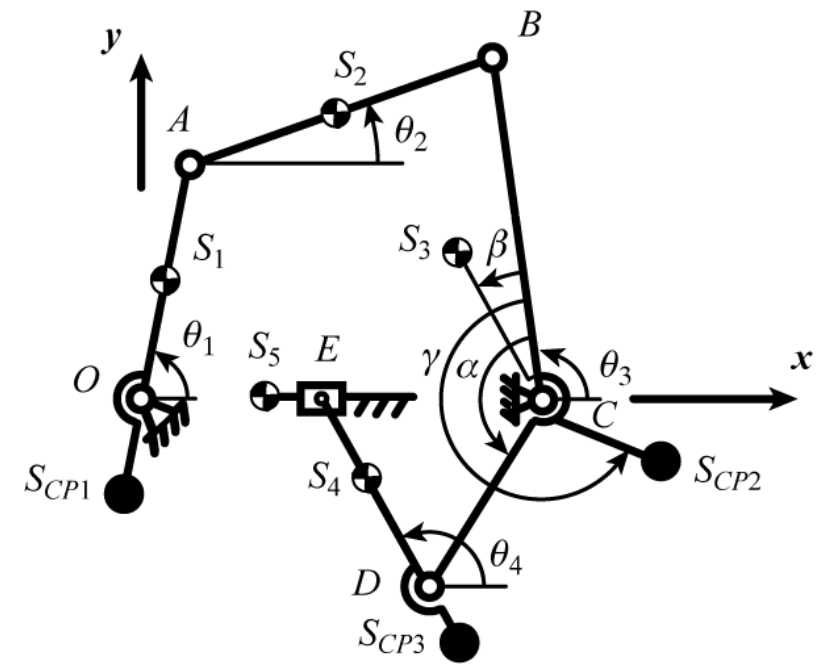

Fig. 4. The balanced four-bar linkage with the class-two RRP Assur group.

In this case, the lengths of added links are the following:

$$
l_{3}^{\prime}=l_{4} \text {. }
$$

Thus, the new part created by added links is a Scott-Russell mechanism, which is attached to the initial linkage at an angle of $\alpha$.

The relations between link accelerations are the following:

$$
\dot{\theta}_{3}=-\dot{\theta}_{4} \text {. }
$$

Let us now derive the expression of the shaking force $\mathbf{F}_{s h}$ of such a mechanism:

$$
\mathbf{F}_{s h}=\sum_{i=1}^{5} m_{i} \ddot{\mathbf{d}}_{S i}
$$

where $m_{i}$ is the mass of the link $i$ and $\ddot{\mathbf{d}}_{S i}$ the translational acceleration of the centre of mass $S_{i}$. Developing and simplifying, one obtains:

$$
\mathbf{F}_{s h}=\left(m_{1} \frac{r_{1}}{l_{1}}+m_{2} \frac{l_{2}-r_{2}}{l_{2}}\right) \ddot{\mathbf{d}}_{A}+m_{2} \frac{r_{2}}{l_{2}} \ddot{\mathbf{d}}_{B}+m_{3} \ddot{\mathbf{d}}_{S 3}+\left(m_{4}+m_{5}\right) \ddot{\mathbf{d}}_{D}+\left(m_{4} \frac{r_{4}}{l_{4}}+m_{5}\right) \ddot{\mathbf{d}}
$$

where $r_{i}$ and $l_{i}$ are the algebraic values of the norm of vectors $\mathbf{r}_{i}$, and $\mathbf{l}_{i}$, respectively,

$$
\begin{gathered}
\ddot{\mathbf{d}}=l_{5}\left(\ddot{\theta}_{5}\left[\begin{array}{c}
-\sin \theta_{5} \\
\cos \theta_{5}
\end{array}\right]-\dot{\theta}_{5}^{2}\left[\begin{array}{c}
\cos \theta_{5} \\
\sin \theta_{5}
\end{array}\right]\right), \\
\ddot{\mathbf{d}}_{S 3}=r_{3}\left(\ddot{\theta}_{3}\left[\begin{array}{c}
-\sin \left(\theta_{3}+\beta\right) \\
\cos \left(\theta_{3}+\beta\right)
\end{array}\right]-\dot{\theta}_{3}^{2}\left[\begin{array}{c}
\cos \left(\theta_{3}+\beta\right) \\
\sin \left(\theta_{3}+\beta\right)
\end{array}\right]\right) .
\end{gathered}
$$

and $\ddot{\mathbf{d}}_{D}$ represent the acceleration of point $D$. Its expression is: 


$$
\ddot{\mathbf{d}}_{D}=l_{3}^{\prime}\left(\ddot{\theta}_{3}\left[\begin{array}{c}
-\sin \left(\theta_{3}+\alpha\right) \\
\cos \left(\theta_{3}+\alpha\right)
\end{array}\right]-\dot{\theta}_{3}^{2}\left[\begin{array}{c}
\cos \left(\theta_{3}+\alpha\right) \\
\sin \left(\theta_{3}+\alpha\right)
\end{array}\right]\right) .
$$

The shaking force $\mathbf{F}_{s h}$ may be cancelled through the addition of three counterweights positioned at points $S_{C P i}$ (Fig. 4), with masses $m_{C P i}(i=1,2,3)$. With such counterweights, the expression of the shaking force becomes:

$$
\mathbf{F}=\mathbf{F}_{s h}+\mathbf{F}_{C W}=\mathbf{F}_{s h}+m_{C P 1} \frac{r_{C P 1}}{l_{1}} \ddot{\mathbf{d}}_{A}+m_{C P 2} \ddot{\mathbf{d}}_{C P 2}+m_{C P 3} \ddot{\mathbf{d}}_{D}+m_{C P 3} \frac{r_{C P 3}}{l_{4}} \ddot{\mathbf{d}},
$$

where $r_{C P i}$ is the algebraic values of the norm of vectors $\mathbf{r}_{\mathbf{C P} i}$, and

$$
\ddot{\mathbf{d}}_{C P 2}=r_{C P 2}\left(\ddot{\theta}_{3}\left[\begin{array}{c}
-\sin \left(\theta_{3}+\gamma\right) \\
\cos \left(\theta_{3}+\gamma\right)
\end{array}\right]-\dot{\theta}_{3}^{2}\left[\begin{array}{c}
\cos \left(\theta_{3}+\gamma\right) \\
\sin \left(\theta_{3}+\gamma\right)
\end{array}\right]\right) .
$$

Thus the shaking force is cancelled if the distribution of the masses is as follows:

$$
\begin{gathered}
m_{C P 1}=-\frac{l_{1}}{r_{C P 1}}\left(m_{1} \frac{r_{1}}{l_{1}}+m_{2} \frac{l_{2}-r_{2}}{l_{2}}\right), \\
m_{C P 3}=-\frac{l_{4}}{r_{C P 3}}\left(m_{4} \frac{r_{4}}{l_{4}}+m_{5}\right), \\
\tan \gamma=\frac{m_{3} r_{3} \sin \beta+\left(m_{4}+m_{5}\right) l_{3}^{\prime} \sin \alpha}{m_{2} l_{3} r_{2} / l_{2}+m_{3} r_{3} \cos \beta+\left(m_{4}+m_{5}\right) l_{3} \cos \alpha}, \\
m_{C P 2}=\sqrt{\frac{\left(m_{3} r_{3} \sin \beta+\left(m_{4}+m_{5}\right) l_{3}^{\prime} \sin \alpha\right)^{2}+\left(m_{2} l_{3} r_{2} / l_{2}+m_{3} r_{3} \cos \beta+\left(m_{4}+m_{5}\right) l_{3}^{\prime} \cos \alpha\right)^{2}}{r_{C P 2}^{2}}} .
\end{gathered}
$$

\subsection{Shaking moment balancing}

With regard to the shaking moment $M$, expressed at point $O$, we have:

$$
M=\sum_{i=1}^{5} m_{i}\left(x_{S i} \ddot{y}_{S i}-y_{S i} \ddot{x}_{S i}+k_{i}^{2} \ddot{\theta}_{i}\right)+\sum_{i=1}^{3} m_{C P i}\left(x_{S C P i} \ddot{y}_{S C P i}-y_{S C P i} \ddot{x}_{S C P i}\right)
$$

where $x_{S i}, y_{S i}, \ddot{x}_{S i}$ and $\ddot{y}_{S i}$ are the positions and accelerations along $\boldsymbol{x}$ and $\boldsymbol{y}$ axes of points $S_{i}$, respectively, and $x_{S C P i}, y_{S C P i}, \ddot{x}_{S C P i}$ and $\ddot{y}_{S C P i}$ are the positions and accelerations along $\boldsymbol{x}$ and $\boldsymbol{y}$ axes of points $S_{C P i}$, respectively, $k_{i}$ is the radius of gyration of link $i$.

Now, let us consider as in the previous case, that link 2 is a physical pendulum and that the input speed is constant.

Taking into account Eqs. (20) and (21), one can simplify Eq. (39) as:

$$
M=I_{3} \ddot{\theta}_{3}+I_{4} \ddot{\theta}_{4}
$$

where

$$
\begin{gathered}
I_{3}=m_{3}\left(k_{3}^{2}+r_{3}^{2}\right)+m_{2} \frac{r_{2}}{l_{2}} l_{3}^{2}+\left(m_{4}+m_{5}+m_{C P 3}\right) l_{3}^{\prime 2}+m_{C P 2} r_{C P 2}^{2}, \\
I_{4}=m_{4}\left(k_{4}^{2}+r_{4}^{2}\right)+m_{5} l_{4}^{2}+m_{C P 3} r_{C P 3}^{2} .
\end{gathered}
$$

Introducing eq. (30) in this expression, we find:

$$
M=\left(I_{3}-I_{4}\right) \ddot{\theta}_{3} .
$$

Thus, the mechanism will be moment balanced if:

$$
I_{3}=I_{4}
$$

which can be obtained using a design of link 4 for which the radius of gyration should be equal to 


$$
k_{4}=\sqrt{\frac{I_{3}-m_{4} r_{4}^{2}-m_{5} l_{4}^{2}-m_{C P 3} r_{C P 3}^{2}}{m_{4}}} .
$$

It should be mentioned that, in order to avoid the singular configurations of the added structure, the value of angle $\alpha$ should be chosen carefully during the design process.

The next section presents two illustrative examples of the proposed balancing technique.

\section{Illustrative examples and numerical simulations}

\subsection{Balancing by adding a class-two RRR Assur group}

Let us carry out the complete shaking force and shaking moment balancing of a four-bar linkage with parameters given in table 1. The simulations of the proposed mechanism have been carried out using ADAMS software and the obtained results are shown in Fig. 5 (full line).

Now we add the RRR Assur group with prescribed distribution of the center of masses and inertia. Its geometric and mass properties are given in table 2 and the location and mass of the added counterweights are given in table 3 . The radii of gyration of elements 4 and 5 and the mass of the counterweight $m_{C P 2}$ are not expressed in these tables as they depend on the value of angle $\alpha$ (Fig. 3). Their variations as a function of $\alpha$ are shown in Fig. 6. In these figures, the values of $\alpha$ are bounded between -60 and $180 \mathrm{deg}$ in order to avoid the RRR Assur group to cross a singularity during the motion. In Fig. 5 (dotted line), it is shown that after the addition of the Assur group, the shaking force and shaking moment are cancelled.

Table 1. Four-bar linkage's parameters.

\begin{tabular}{|l|l|l|l|}
\hline Parameters & link 1 & link 2 & link 3 $(\beta=0 \mathrm{deg})$ \\
\hline$l_{i}(\mathrm{~m})$ & 0.2 & 0.27 & 0.25 \\
\hline$m_{i}(\mathrm{~kg})$ & 1 & 1 & 1 \\
\hline$r_{i}(\mathrm{~m})$ & 0.1 & 0.135 & 0.125 \\
\hline$k_{i}(\mathrm{~m})$ & 0.056 & 0.135 & 0.086 \\
\hline
\end{tabular}

Table 2. Parameters defining the RRR Assur group.

\begin{tabular}{|l|l|l|}
\hline Parameters & link 4 & link 5 \\
\hline$l_{i}(\mathrm{~m})$ & 0.8 & 0.25 \\
\hline$m_{i}(\mathrm{~kg})$ & 1.5 & 1 \\
\hline$r_{i}(\mathrm{~m})$ & 0.4 & 0.125 \\
\hline
\end{tabular}

Table 3. Parameters defining the counterweights.

\begin{tabular}{|l|l|l|l|}
\hline Parameters & Counterweight 1 & Counterweight 2 & Counterweight 3 \\
\hline$r_{C P i}(\mathrm{~m})$ & -0.1 & 0.25 & -0.125 \\
\hline$m_{i}(\mathrm{~kg})$ & 2 & - & 2.5 \\
\hline
\end{tabular}




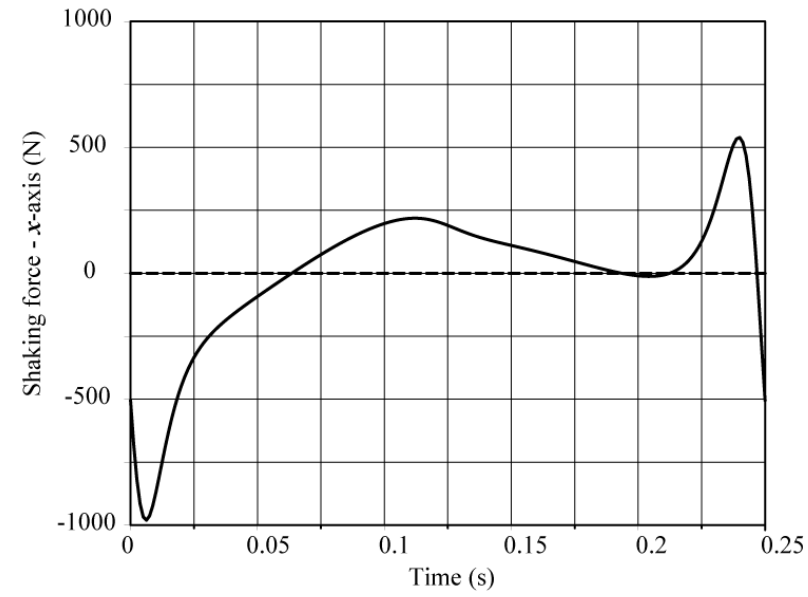

(a) Shaking force along $\boldsymbol{x}$-axis.

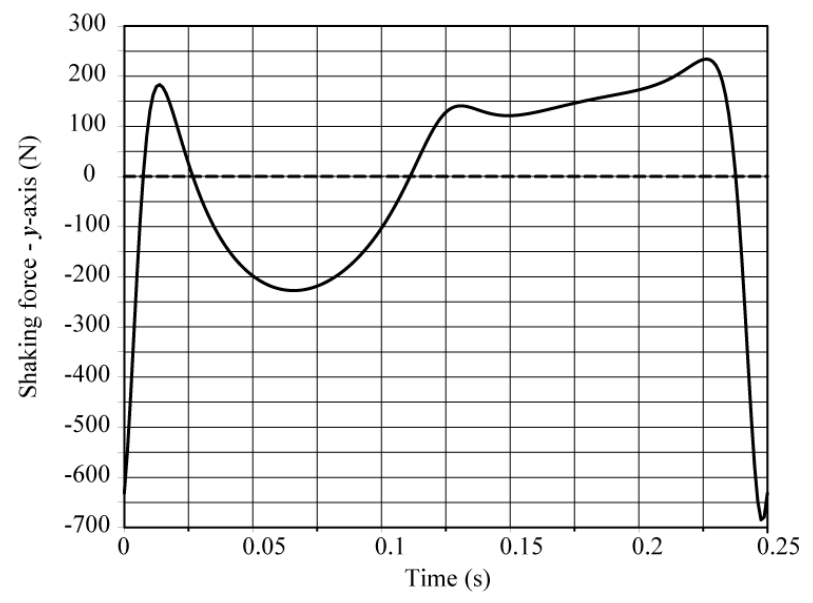

(b) Shaking force along $\boldsymbol{y}$-axis.

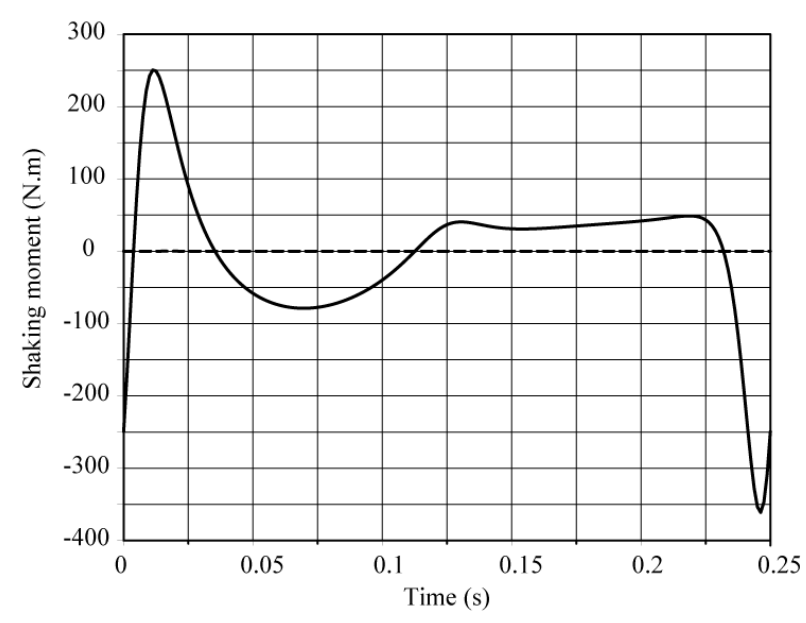

(c) Shaking moment along $z$-axis.

Fig. 5. Shaking force and shaking moment of the four-bar mechanism before (full line) and after (dotted line) balancing.

As angle $\alpha$ is a free parameter that has only influence on the values $k_{4}, k_{5}$ and $m_{C P 2}$, it can be chosen so that it minimizes one supplementary criterion. In the remainder of the paper, this criterion is chosen to be the linkage input torque [39], [40]. It should however be mentioned that angle $\alpha$ could be used to minimize another criterion such as the power consumption, the energy, etc.

It should also be noted that the input torque $\tau$, i.e. the torque requested by the actuator to move the mechanism, is computed in the two illustrative examples by using the Lagrange equations [40]:

$$
\tau=\frac{d}{d t}\left(\frac{\partial L}{\partial \dot{\theta}_{1}}\right)-\frac{\partial L}{\partial \theta_{1}}
$$

where $L=T-V$ is the Lagrangian of the system, $V$ is the potential energy (equal to 0 in absence of gravity) and $T$ is the kinetic energy:

$$
T=\frac{1}{2} \sum_{i} m_{i}\left(\dot{x}_{S i}^{2}+\dot{y}_{S i}^{2}\right)+\frac{1}{2} \sum_{j} I_{j} \dot{\theta}_{j}^{2},
$$

$\dot{x}_{S i}, \dot{y}_{S i}$ being the velocities along $\boldsymbol{x}$ and $\boldsymbol{y}$ axes of any centres of masses (for links and counterweights).

In Fig. 7, the maximum of the input torque absolute value of as a function of angle $\alpha$ is shown. Thus, it is possible to see that if the value of $\alpha$ is chosen arbitrarily, the input torques can 
grow up to $2140 \mathrm{Nm}$ (for $\alpha=0 \mathrm{deg}$ ). It also appears that the input torque will be minimal if $\alpha=$ $164 \mathrm{deg}$. In this case, the value of the input torque is $1010 \mathrm{Nm}$, i.e. about 2 times less than in the first case.

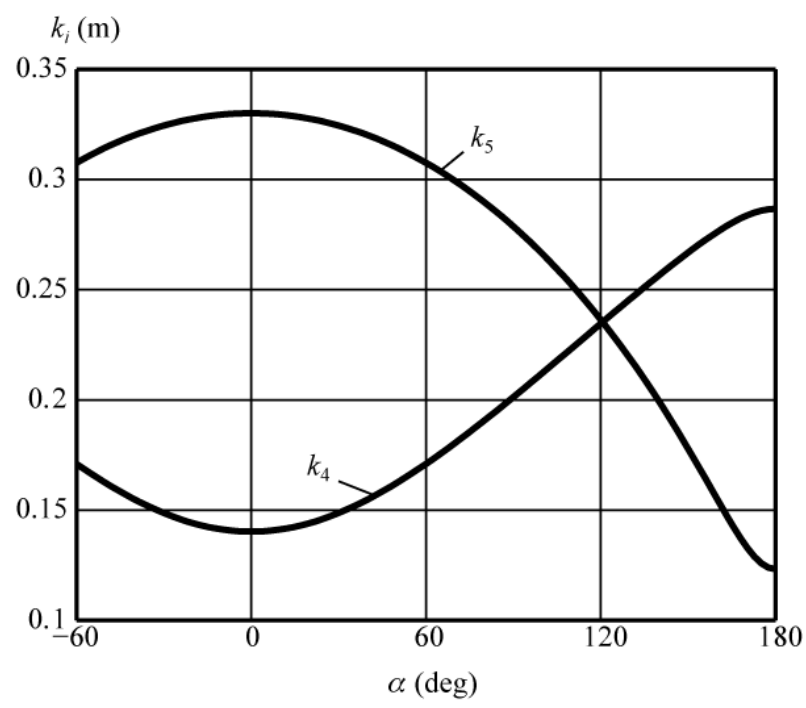

(a) variation of $k_{4}$ and $k_{5}$

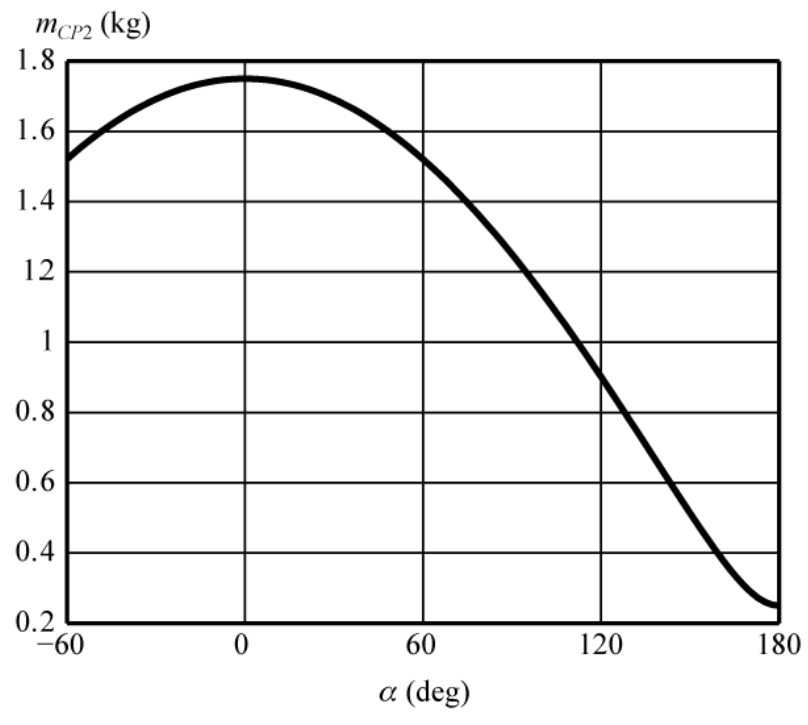

(b) variation $m_{C P 2}$

Fig. 6. Variation of the values of parameters $k_{4}, k_{5}$ and $m_{C P 2}$ as a function of angle $\alpha$.

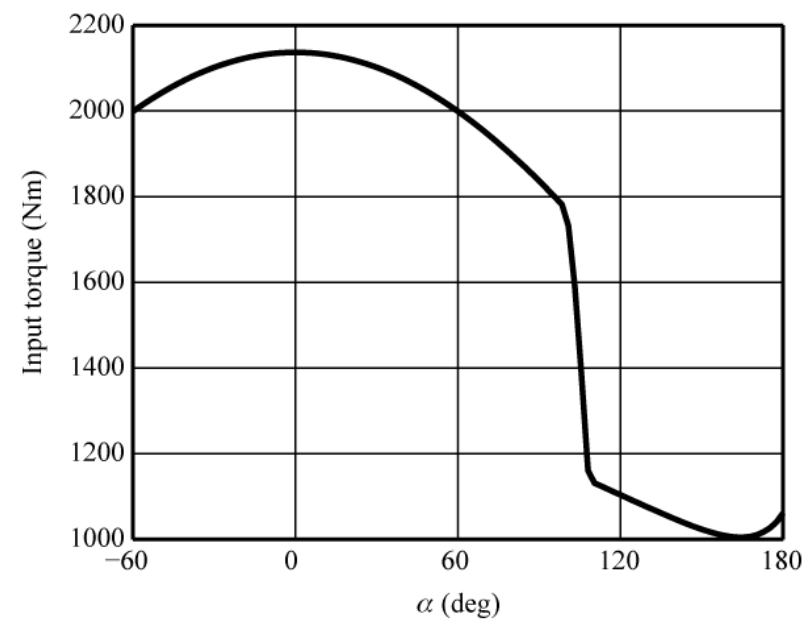

Fig. 7. Variation of the maximal input torque absolute value as a function of angle $\alpha$.

\subsection{Balancing by adding a class-two RRP Assur group}

We now propose obtaining the complete shaking force and shaking moment balancing of the same mechanism by adding a class-two RRP Assur group. Its geometric and mass properties are given in table 4 and the location and mass of the added counterweights are given in table 5 . The radii of gyration of element 4 and the mass of the counterweight $m_{C P 2}$ are not expressed in these tables as they depend on the value of angle $\alpha$ (Fig. 4). Their variations as a function of $\alpha$ are shown in Fig. 8. In these figures, the values of $\alpha$ are bounded between 25 and 100 deg or 205 and $280 \mathrm{deg}$ in order to avoid the RRP Assur group to cross a singularity during the motion. The simulations of the proposed mechanism have been carried out using ADAMS software and the results are similar to the previous case shown in Fig. 5. 
Table 4. Parameters defining the RRP Assur group.

\begin{tabular}{|l|l|l|}
\hline Parameters & link 4 $\left(\alpha=-90^{\circ}\right)$ & link 5 \\
\hline$l_{i}(\mathrm{~m})$ & 0.25 & 0.25 \\
\hline$m_{i}(\mathrm{~kg})$ & 0.35 & 0.1 \\
\hline$r_{i}(\mathrm{~m})$ & 0.125 & - \\
\hline
\end{tabular}

Table 5. Parameters defining the counterweights.

\begin{tabular}{|l|l|l|l|}
\hline Parameters & Counterweight 1 & Counterweight 2 & Counterweight 3 \\
\hline$r_{C P i}(\mathrm{~m})$ & -0.1 & 0.25 & -0.125 \\
\hline$m_{i}(\mathrm{~kg})$ & 2 & - & 0.55 \\
\hline
\end{tabular}

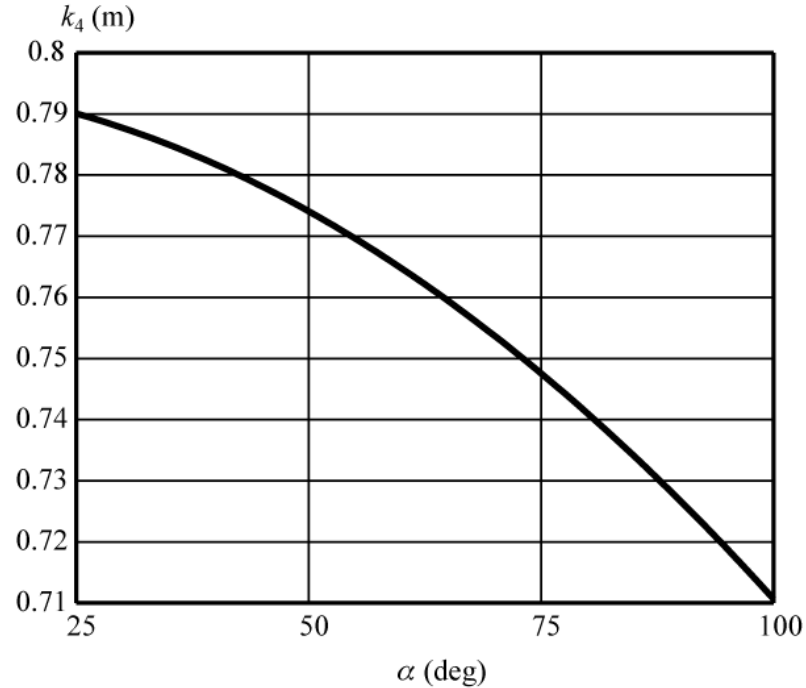

(a) variation of $k_{4}$ for $\alpha \in[25100] \mathrm{deg}$

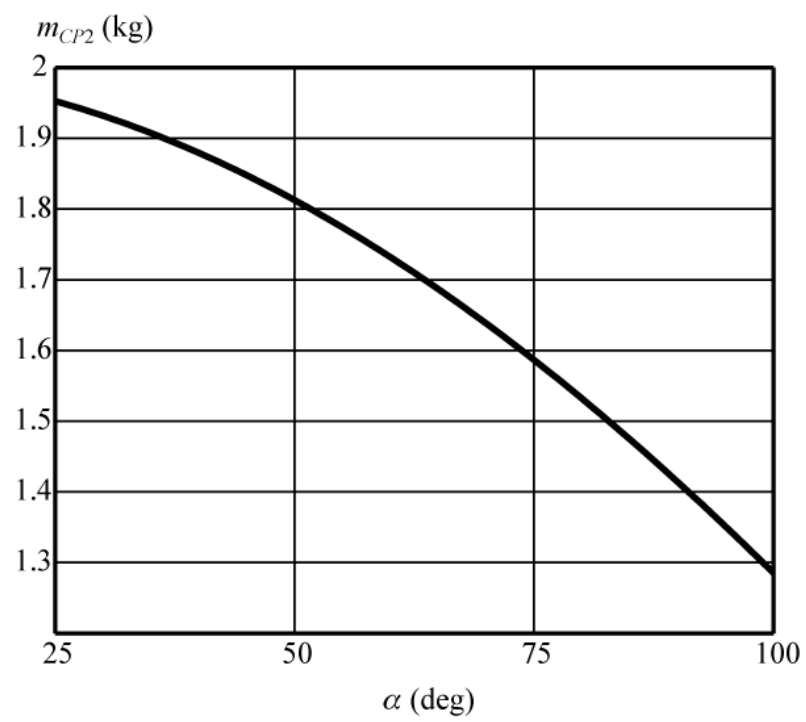

(c) variation $m_{C P 2}$ for $\alpha \in[25100] \mathrm{deg}$

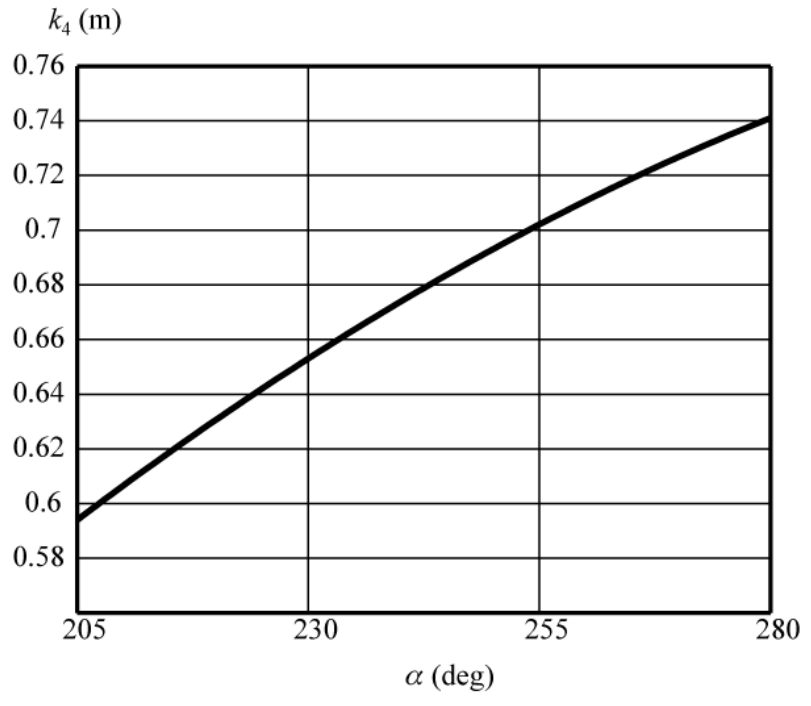

(b) variation of $k_{4}$ for $\alpha \in[205280] \mathrm{deg}$

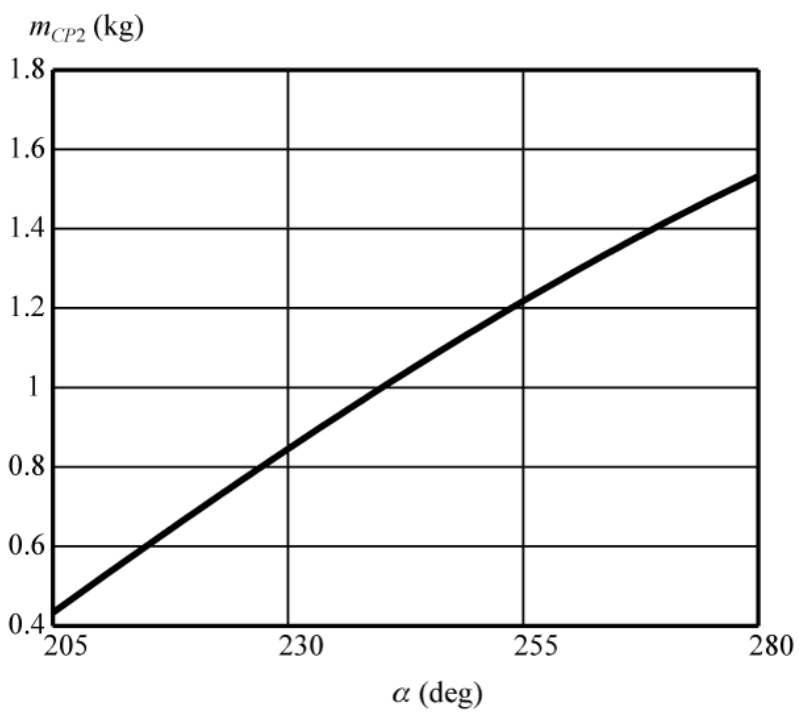

(d) variation $m_{C P 2}$ for $\alpha \in[205280] \mathrm{deg}$

Fig. 8. Variation of the values of parameters $k_{4}$ and $m_{C P 2}$ as a function of angle $\alpha$. 


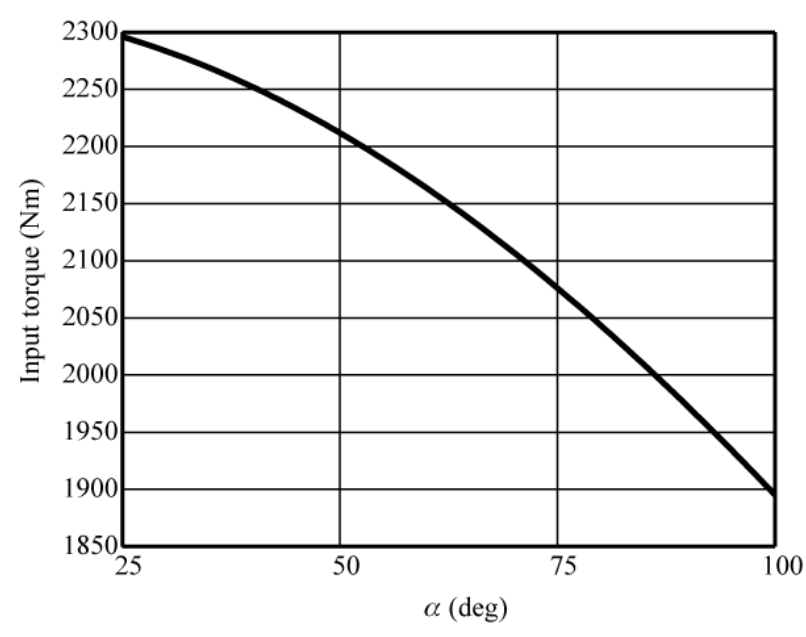

(a) for $\alpha \in[25100] \mathrm{deg}$

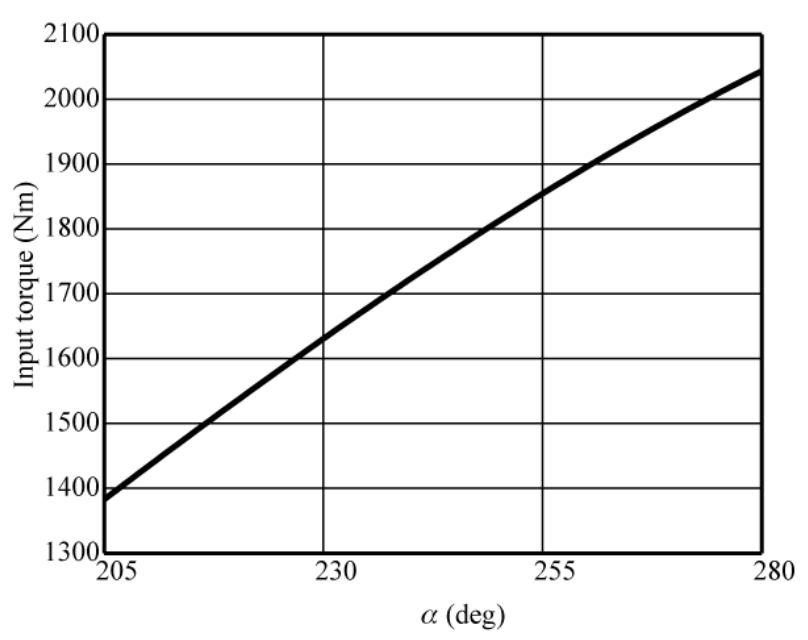

(b) for $\alpha \in[205280] \mathrm{deg}$

Fig. 9. Variation of the maximal input torque absolute value as a function of angle $\alpha$.

As it was mentioned above, the angle $\alpha$ is a not fixed design parameter and it can be found from minimization of the input torque of the mechanism. In Fig. 9, maximum of the input torque absolute value as a function of angle $\alpha$ is shown. It is possible to see that if the value of $\alpha$ is chosen arbitrarily, the input torques can grow up to $2300 \mathrm{Nm}$ (for $\alpha=25 \mathrm{deg}$ ). It also appears that the input torque will be minimal if $\alpha=205 \mathrm{deg}$. In this case, the value of the input torque is $1380 \mathrm{Nm}$, i.e. about 1.7 times less than in the first case.

\section{Conclusion}

In this study, a new balancing method is proposed, which allows the shaking force and shaking moment cancellation in the in-line four-bar linkages with constant input speed. It is carried out without counter-rotating masses because, in this balancing approach, the properties of the self-balanced four-bar linkage with prescribed geometric parameters are combined with the principle of the dynamic substitution of link by concentrated masses. The suggested balancing is obtained by adding a class-two RRR or RRP Assur groups with prescribed geometrical parameters to the initial mechanism. The simulations carried out using ADAMS software have shown that the obtained six-bar mechanism transmits no inertia loads to its surroundings, i.e. the sum of all ground bearing forces and their moments are eliminated.

\section{References}

[1] Fischer, O., 1902. Über die reduzierten Systeme und die Hauptpunkte der Glieder eines Gelenkmechanismus, Zeif. für Math. and Phys., 47, 429-466.

[2] Artobolevskii, I.I., Edelshtein, B.V., 1935. Methods of inertia calculation for mechanisms of agricultural machines (Russian), Moscow, Ed. Selkhozizdate.

[3] Crossley, F.R.E., 1954. Dynamics in Machines, Roland Press, New York.

[4] Talbourdet, G.L., Shepler, P.R., 1941. Mathematical solution of 4-bar linkages - IV, Balancing of linkages, Machine Design 13, 73-77.

[5] Smith, M.R., Maunder, L., 1967. Inertia forces in a four-bar linkage, in: Mechanical Engineering Science 9(3), 218-225. 
[6] Berkof, R.S., Lowen, G.G., 1969. A new method for completely force balancing simple linkages, TransASME, Eng. Ind., 91B(1), 21-26.

[7] Hilpert, H., 1968. Weight balancing of precision mechanical instruments, Mechanisms 3(4), 289-302.

[8] Lowen, G.G., Berkof, R.S., 1971. Theory of Shaking Moment Optimization of ForceBalanced Four-Bar Linkages, TransASME, MECH 12.

[9] Lowen, G.G., Berkof, R.S., 1970. Determination of Force-Balanced Four-Bar Linkages with Optimum Shaking Moment Characteristics, TransASME, MECH 8.

[10] Berkof, R.S., Lowen, G.G., 1971. Theory of shaking moment optimization of forcebalanced four-bar linkages, TransASME 93B(1), 53-60.

[11] Wiederrich, J.L., Roth, B., 1976. Momentum balancing of four-bar linkages, TransASME 98B(4), 1289-1295.

[12] Elliot, J.L., Tesar, D., 1977. The theory of torque, shaking force and shaking moment balancing of four link mechanisms, TransASME 99B(3), 715-722.

[13] Carson, W.L., Stephens, J.M., 1978. Feasible parameter design spaces for force and rootmean-square moment balancing on in-line 4R 4-bar linkage synthesized for kinematic criteria, Mech. and Mach. Theory 13(6), 649-658.

[14] Haines, R.S., 1981. Minimum r.m.s. shaking moment or driving torque of a force-balanced four-bar linkage using feasible counterweights. Mechanism and Machine theory 16(3), 185-190.

[15] Schcepetilnikov, V.A., 1968. The determination of the mass centers of mechanisms in connection with the problem of mechanism balancing, Mechanisms 3(4), 367-389.

[16] Arakelian, V., Dahan, M., 2001. Partial shaking moment balancing of fully shaking force balanced linkages. Journal of Mechanism and Machine Theory 36(11-12), 1241-1252.

[17] Arakelian, V., Dahan, M., Smith, M., 2001. Complete Shaking Force and Partial Shaking Moment Balancing of Planar Four-bar Linkages. Journal of Multi-body Dynamics, UK, IMechE 215 Part K, 31-34.

[18] Zhang, S., 1994. A constitutive method of objective function for the dynamic optimum balance of shaking force in linkage, Mech. and Mach. Theory 29(6), 829-835.

[19] Zang, S., Chen, J., 1995. The optimum balance of shaking force and shaking moment of linkages, Mech. and Mach. Theory 30(4), 589-597.

[20] Qi, N.M., Pennestri, E., 1991. Optimum balancing of four-bar linkages, Mech. and Mach. Theory 26(3), 337-348.

[21] Chaudhary, H., Saha, S.K., 2007. Balancing of four-bar linkages using maximum recursive dynamic algorithm, Mech. and Mach. Theory 42, 216-232.

[22] Kamenskii, V.A., 1968. On the question of the balancing of planar linkages. Journal of Mechanisms 3, 303-322.

[23] Berkof, R.S., 1973. Complete force and moment balancing inline four-bar linkages, Mech. and Mach. Theory 8, 397-410.

[24] Bagci, C., 1982. Complete shaking force and shaking moment balancing of link mechanisms using balancing idler loops, Trans. ASME 104, 482-493.

[25] Ye, Z., Smith, M.R., 1994. Complete balancing of planar linkages by an equivalence method, Mech. and Mach. Theory 29(5), 701-712.

[26] Arakelian, V., Smith, M.R., 1999. Complete shaking force and shaking moment balancing of linkages, Mech. and Mach. Theory 34(8), 1141-1153.

[27] Feng, G., 1991. Complete shaking force and shaking moment balancing of 17 types of eight-bar linkages only with revolute pairs, Mechanisms and Machine Theory 26(2), 197206.

[28] Berestov, L.V., 1977. Comparative analysis of the reactions in the kinematic pairs of the four-bar linkages for the different balancing methods, Russian Journal "Mekhanika Machin", Moscow, Ed. Nauka, 61-70. 
[29] Dresig, H., Naake, S., Rockausen, L., 1994. Vollständiger und harmonischer Ausgleich ebener Mechanismen, VDI Verlag, Düsseldorf.

[30] Esat, I., Bahai, H., 1999. A theory of complete force and moment balancing of planar linkage mechanisms, Mechanisms and Machine Theory 34(6), 903-922.

[31] Arakelian, V., Dahan, M., 2002. Patent FR2817008, May 24.

[32] Arakelian, V., Smith, M., 2005. Shaking force and shaking moment balancing of mechanisms: an historical review with new examples, Transactions of the ASME, Journal of Mechanical Design 127, 334-339.

[33] Kochev, I.S., 1990. Full shaking moment balancing of planar linkages by a prescribed input speed fluctuation, Mech. and Mach. Theory 25(4), 459-466.

[34] Leinonen, T. 1991, "Terminology for the theory of machines and mechanisms," Mechanism and Machine Theory, 26, 1991

[35] Ricard, R., Gosselin, C.M., 2000. On the development of reactionless parallel manipulators, in: Proceedings of the ASME Design Engineering Technical Conference, Baltimore, Maryland, September 10-13.

[36] Wu, Y., Gosselin, C.M., 2004, "Synthesis of reactionless spatial 3-dof and 6-dof mechanisms without separate counter-rotations," International Journal of Robotics Research 23(6), 625-642.

[37] Gosselin, C., Vollmer, F., Côté, G. and Wu, Y., 2004, "Synthesis and design of reactionless three-degree-of-freedom parallel mechanisms," IEEE Transactions on Robotics and Automation 20(2), 191-199.

[38] Gosselin, C., Moore, B. and Schicho, J., 2009, "Dynamic balancing of planar mechanisms using toric geometry," Journal of Symbolic Computation 44(9), 1346-1358.

[39] Demeulenaere, B. and Berkof, R.S., 2008, "Improving machine drive dynamics: a structured design approach towards balancing," ASME Journal of Mechanical Design, 130(8).

[40] Berkof, R.S., 1979, "The input torque in linkages," Mechanism and Machine Theory, 14(1), 61-73. 


\section{Figures captions}

Fig. 1. A general in-line four-bar mechanism.

Fig. 2. The three kinds of shaking force and shaking moment balanced four-bar mechanisms. (a) Case I: $l_{1}=d$ and $l_{2}=l_{3}$. (b) Case II: $l_{1}=l_{3}$ and $l_{2}=d$. (c) Case III: $l_{1}=l_{2}$ and $l_{3}=d$.

Fig. 3. The balanced mechanism with the class-two RRR Assur group.

Fig. 4. The balanced four-bar linkage with the class-two RRP Assur group.

Fig. 5. Shaking force and shaking moment of the four-bar mechanism before (full line) and after (dotted line) balancing. (a) Shaking force along $\boldsymbol{x}$-axis. (b) Shaking force along $\boldsymbol{y}$-axis. (c) Shaking moment along $z$-axis.

Fig. 6. Variation of the values of parameters $k_{4}, k_{5}$ and $m_{C P 2}$ as a function of angle $\alpha$. (a) variation of $k_{4}$ and $k_{5}$. (b) variation $m_{C P 2}$.

Fig. 7. Variation of the maximal input torque absolute value as a function of angle $\alpha$.

Fig. 8. Variation of the values of parameters $k_{4}$ and $m_{C P 2}$ as a function of angle $\alpha$. (a) variation of $k_{4}$ for $\alpha \in[25100]$ deg. (b) variation of $k_{4}$ for $\alpha \in$ [205 280] deg. (c) variation $m_{C P 2}$ for $\alpha \in$ [25 100] deg. (d) variation $m_{C P 2}$ for $\alpha \in$ [205 280] deg.

Fig. 9. Variation of the maximal input torque absolute value as a function of angle $\alpha$. (a) for $\alpha \in$ [25 100] deg. (b) for $\alpha \in[205280]$ deg.

\section{Tables captions}

Table 1. Four-bar linkage's parameters.

Table 2. Parameters defining the RRR Assur group.

Table 3. Parameters defining the counterweights.

Table 4. Parameters defining the RRP Assur group.

Table 5. Parameters defining the counterweights. 